\title{
EFFECTIVENESS OF CARDIOPULMONARY RESUSCITATION DEPENDING ON LIFEGUARD'S LEVEL OF EXHAUSTION
}

\author{
Remigiusz Olejniczak \\ University of Szczecin, Institute of Spatial Management and Socio-Economic Geography \\ Address for coprespondence: \\ Remigiusz Olejniczak \\ Pracownia Bezpieczeństwa Wodnego \\ Mickiewicza 18, Szczecin, Poland \\ Email: remigiusz.olejniczak@usz.edu.pl
}

\begin{abstract}
Ahstract Rescue operation consists of many connected parts which are called rescue chain links. The quality of the whole operation depends on the accuracy of execution and compliance with each link. Undue hurry, sluggishness or excessive exhaustion of lifeguard may decrease the quality of the performed resuscitation procedures, which are an important element of the whole rescuing process. The presence of a qualified lifeguard or rescue team is essential to the rescuing process. Situations in which lifeguard is on duty as a single unit are permitted in Polish legal regulations. In such cases, up to the point of transferring the victim to emergency medical services, rescue operation lies in the hands of a single lifeguard. The aim of this report is a comparative analysis of the quality of two-minute CPR procedures performed on QCPR anatomical models (Resusci Little Anne), in case of a one-person rescue operation at the swimming pool. 22 students of Water Safety, University of Szczecin took part in the experiment. The results of the experiment showed that the exhaustion of the lifeguard did not have a substantial impact on the quality and effectiveness of the rescue procedures. The study was conducted in conditions isolated from fatigue and after a rescue operation performed in water.
\end{abstract}

Key WOrds cardiopulmonary resuscitation, aquatic safety, physical capacity

\section{Introduction}

Deaths on Earth are still too often caused by cardiopulmonary arrest. 55-113 out of 100,000 people die yearly due to this reason, i.e. 350,000-750,000 people in the world (Grasner, Bossaert, 2013). World Health Organization (WHO) evaluates that every hour more than 40 people die from drowning, which makes 372,000 deaths yearly (Global Report on Drowning, 2014). A great amount of people dies because they do not receive aid at the right time from the first-contact lifeguard. Expertise and abilities of basic resuscitation procedures allow for so-called "buying time for the victim", through performing chest compressions and rescue breaths on the victim. Abandonment of these actions in time above 4 min. may result in irreparable consequences in human organism, which will affect the quality of their life. The commonness of training and post-training exercises is still not high enough. There is a lot of areas in the world, in which people do not know CPR (cardiopulmonary resuscitation) activities; there are even areas in 
which people have not even heard of them. Another problem is the decision making in situations requiring first aid rescue operations. Restraint, fear of infection, stress and fear of legal implications are only a few psychological mechanisms affecting the abandonment of rescue operations (Savastano, Vanni, 2011). In most societies, the average time from the emergency call to the arrival of the emergency medical team is 5-8 min. (Lilja et al., 2015) or 8-11 min. from the emergency call to the first defibrillation (Sulzgruber et al., 2015). In this time the survival rate of victims depends on taking CPR and the use of an automatic external defibrillator (AED) by the rescuer.

Main services in Poland established for rescue operations are Emergency Medical Services, State Fire Service, Volunteer Fire Service, Mountain Volunteer Search and Rescue, Water Rescue Services and many other institutions providing professional and social service. In Poland, water safety is managed by entities obtaining permission to perform emergency medical services (Ustawa z 18.08.2011 r. o bezpieczeństwie osób przebywających na obszarach wodnych). These entities are obliged to competent rescue not only in the search, taking and evacuation of the victim or victims, but also in providing qualified first aid (Ustawa z 8.09.2006 r. o Państwowym Ratownictwie Medycznym). Each of the rescuers who provide first aid should remember and implement the "Chain of Survival" (Figure 1) in their actions. The chain of survival sums up the most important activities required to perform effective resuscitation. Most of the Chain's links are related to the victims who have had cardiopulmonary arrest as an originally cardiogenic result, but also as a result of asphyxiation (Wytyczne resuscytacji, 2015, p. 12).

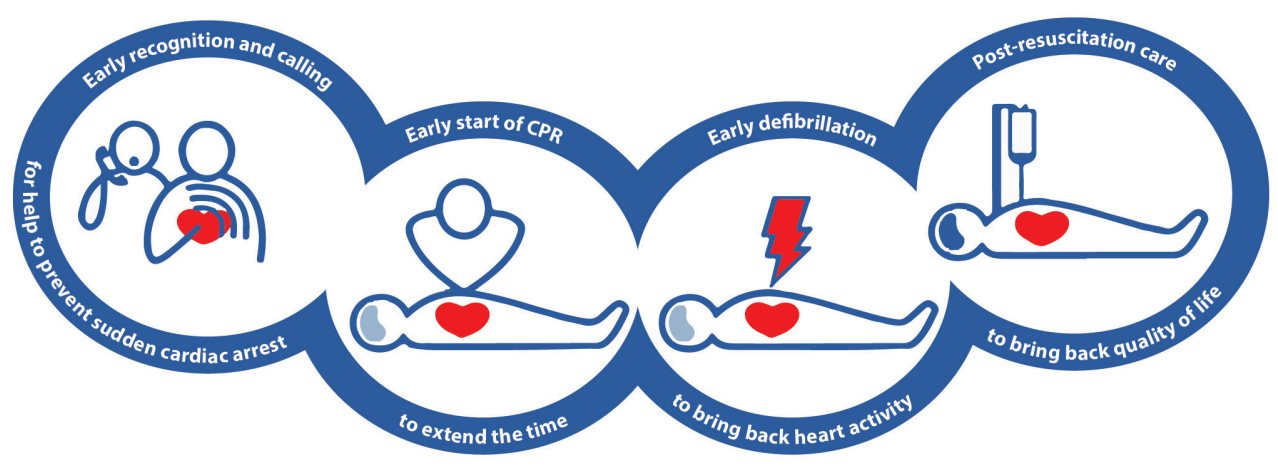

Figure 1. Chain of survival

In the context of the topic raised in this material, the treatment of cardiac arrest, which occurred in specific locations, deserves attention. These locations include health care facilities, commercial aircraft, sports fields, external environments such as water, high altitude, backfilling and electric shock (Wytyczne resuscytacji, 2015, p. 12). When focusing attention on providing assistance in and around water areas, one should remember about significant differences in performing CPR activities for an unconscious person pulled out of the water (Szpilman et al., 2014) (Figure 2). 


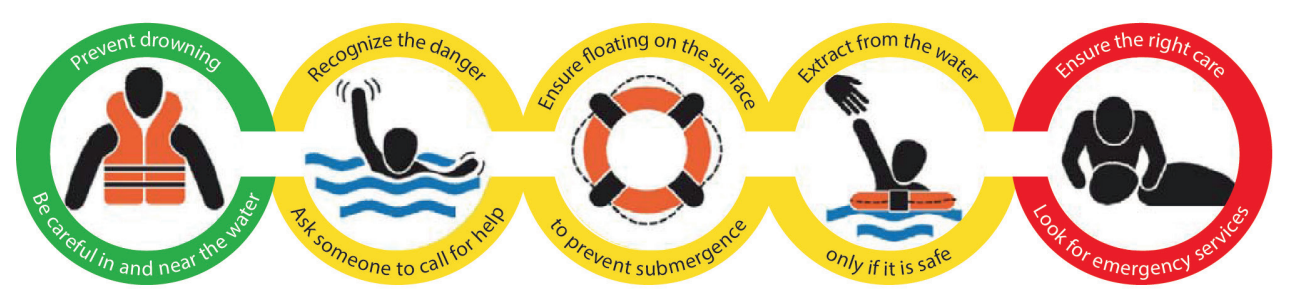

Figure 2. Chain of survival in the case of drowning

The chain of survival in the case of drowning demonstrates five important links related to the improvement of survival rate in drowning (Szpilman et al., 2014). The first two links include drowning prevention and danger recognition (Wallis et al., 2015). The remaining three links relate to ensuring of flotation on surface and extraction from water and undertaking rescue operations, including calling the emergency. The algorithm of the procedure in cases of drowning applies to rescuers with an obligation to provide first aid and people with appropriate training in water rescue (Wytyczne resuscytacji, 2015, p. 12) (Figure 3).

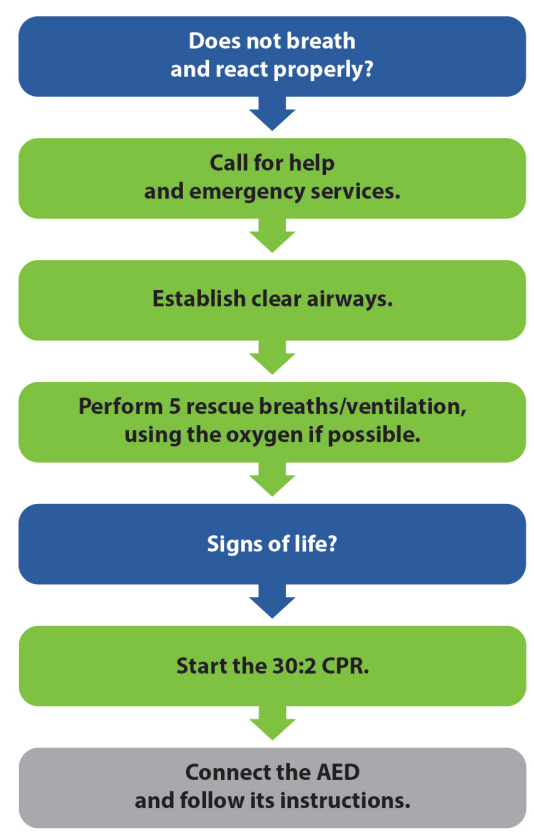

Figure 3. Algorithm of the procedure in cases of drowning applies to rescuers with an obligation to provide first aid 
In the scope of assisting flooded person extracted to the surface of the water, it is recommended to ventilate the injured person in the water, preferably with the help of a rescue buoy. Some of the injured people might react to the rescue breaths given in the water during the evacuation. However, if this does not happen, then due to the difficulties (wave, distance from the shore, equipment support), the rescuer should extract the victim to shore as fast as possible without further ventilation attempts. One of the studies shows a greater survival rate when using ventilation in water (Szpilman et al., 2014). It happens that the lifeguard does not have the support of a second lifeguard or a rescue team. Such cases are reflected in swimming pools up to 25 meters in length, where regulations allow the presence of one lifeguard (Rozporządzenie MSW z dnia 23 stycznia 2012 r.). In such cases, a single lifeguard undertakes rescue operations both in and outside the water. The issue of performing rescue procedures after executing rescue operations in the water mainly raises the subject of the quality of these procedures depending on the mental and physical conditions of the rescuer providing aid. Studies on this subject in Poland, with the participation of candidates for Senior Rescuers, show that there are no significant correlations between the fatigue of a rescuer and the effectiveness of CPR treatments (Stanula, 2008). The focus was also given to the dimorphic differences in the context of CPR. It turned out that women get tired much faster during resuscitation, which disrupts the quality of these activities (Sanchez-Lopez, Rovira-Gil, González-García, Ferrer-López, Martínez-Vizcaíno, 2015). In 2019, research was carried out confirming the importance of height above sea level (3,259 m a.s.l.) at which CPR procedures were performed by mountain rescuers. In the case of the "mountain" experiment, it turns out that performing CPR in simulated hypoxia significantly increases the physiological requirements of the rescuer, but does not affect their quality, at least in the first 10 minutes (Carballo-Fazanes et al., 2019). Researchers studying the subject of CPR in water rescue attempted to examine a situation where a first contact rescuer was not trained in water assistance. Our knowledge of the basic BLS algorithm procedures has an impact on the quality of aid and the number of patients who survive cardiac arrest (Sulovic et al., 2018). There is a tendency to shorten the time at which CPR starts. Both in the water and sea rescue, treatments begin on the water. The research results appearing in 2014 assess the innovative ALS rescue concept, based on the operation of a helicopter simulator, where the self-inflating platform Heliboat was used during the action, which enabled the initiation of resuscitation activities on the water, just after extracting the sinking (Winkler et al., 2015). Catarina Qeuiroga took care of the quality and effectiveness of resuscitation procedures after the operation in the swimming pool. Research results from 2014 show that physical fatigue caused by rescuing in the swimming pool negatively affect the quality of the two-minute CPR performance. 27 students participating in the study made mistakes in the number of compressions performed, as well as in the ratio of compression performed to the given breaths. The authors state that CPR treatments are more effective when training of the lifeguards is conducted in conditions similar to those accompanying the actual rescue operation (Queiroga, Barcala-Furelos, Abelairas-Gomez, Garcia-Soidan, 2014). Similar studies were carried out in 2012 in Spain. Based on 60 students (30 women and 30 men) previously trained in water rescue, who, after the effort caused by the rescue operation in inland waters, performed a five-minute CPR at the Resusci Anne anatomical model. The results showed that effort-induced fatigue during open-water rescue has an impact on the total amount and quality of chest compressions and ventilation (Barcala-Furelos, Abelairas-Gomez, Romo-Perez, Palacios-Aguilar, 2013). 


\section{Aim of the study}

The aim of the study was to try and determine the effect of fatigue on the effectiveness of a rescue operation. Comparative analysis of the quality of two-minute CPR treatments on QCPR anatomic models (Resusci Little Anne) in a one-man rescue operation. Comparison of the results of a rescuer performing CPR in two different situations: without inducing fatigue by physical effort and with inducing fatigue by one-man rescue operation.

\section{Research hypotheses}

1. The fatigue of a lifeguard simulated by a rescue operation has a significant impact on the quality and effectiveness of resuscitation procedures.

2. The fatigue of a lifeguard in a simulated rescue operation has a significant impact on some of the selected CPR "indicators".

3. The obtained results of CPR procedures in a state without fatigue, and in fatigue differ statistically significantly.

\section{Material and methods}

The study was carried out in November 2019 among 22 students of Water Safety, Institute of Spatial Management and Socio-Economic Geography of the University of Szczecin. All students are members of the Voluntary Water Rescue Service of West Pomeranian Voivodeship in the rank of Water Rescuee (Ustawa..., 2011). The first part of the experiment was carried out in the Rescue Lab. The second part of the experiment was carried out in a $25 \mathrm{~m}$ long and $2.5 \mathrm{~m}$ deep indoor sports swimming pool. Preparation of the research group consisted of readiness for water rescue classes in the swimming pool. Equipment used in the research: rescue tube, a handheld stopwatch, a hand-held device Polar Vantage M for measuring the pulse rate, DLRG pool rescue dummy, an anatomical model of an adult (Little Anne Laerdal, QCPR) for cardiopulmonary resuscitation and an iPad to generate and collect data. During the part in which the rescuers performed CPR procedures, the application "QCPR Instructor" was used. Thanks to the application on a mobile device, the obtained results were provided by the device in a precise manner. The individual elements of the CPR study were called "indicators". The indicators checked and generated for the assumed purposes and research hypotheses are general index, relaxation, depth of compression, rate of compression, breath share (given as a percentage - \%); the rate of compressions to rescue breaths given (data are given in quantities). The research began with "initial resuscitation" which each student performed at the anatomical model in the Rescue Lab. When approaching the tests, the students were not tired, and their pulse before approaching the rescue dummy did not exceed 72 beats per minute. The CPR procedures performed on the phantom were in line with ERC (European Resuscitation Council) guidelines, which adopt: compression depth about $5 \mathrm{~cm}$, compression frequency 100-120/min, minimizing interruptions in chest compressions, firm ground, proper chest deformation, appropriate work cycle 50/50\% (Wytyczne resuscytacji, 2015, p. 12).

The scenario was in line with ERC guidelines and assumed:

1. Checking the response and correct breathing.

2. Calling for help and emergency medical team.

3. Establishing a clear airway.

4. Performing 5 rescue breaths/ventilation (using oxygen if possible). 
5. Checking for signs of life.

6. Start of CPR 30:2.

The research task assumed a scenario in which the injured person was pulled out of the water WBLS (Water Basic Life Support). There was a person with a telephone in the presence of the rescuer, and no AED was present in the building. The course of the mock rescue operation, in which CPR procedures were used, consisting of control of consciousness and breathing, emergency medical team call, initiation of cardiopulmonary resuscitation from 5 rescue breaths, 30 chest compressions and 2 rescue breaths, 30:2 CPR continuation. The duration of "initial resuscitation" is two minutes, counted from the start of five rescue breaths. Before the preliminary test, all students were trained in first aid according to the guideline of the European Resuscitation Council, during the BLS and AED course (Figure 4).
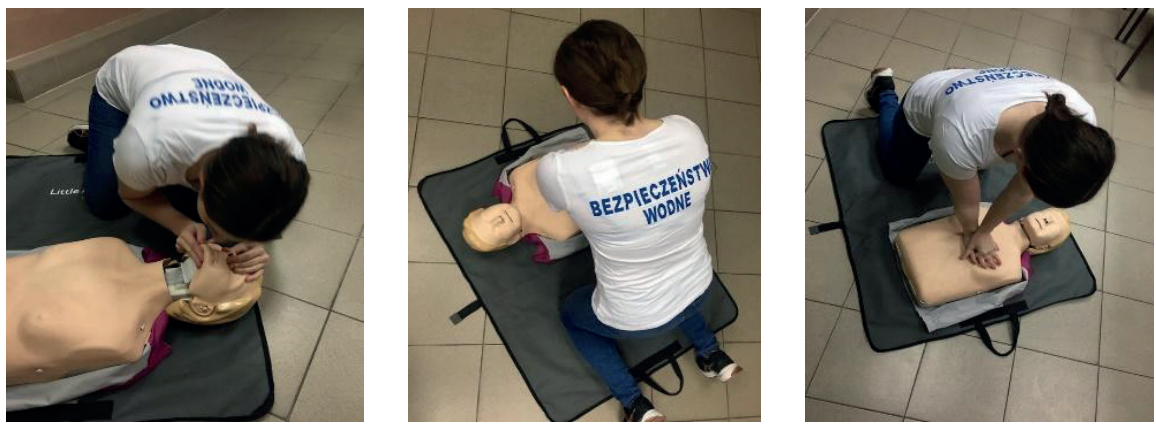

Figur 4 4. Fragments of CPR procedures at the QCPR anatomical model performed by a lifeguard who is not shortly after physical effort

The model of the rescue operation on the basis of which the survey was conducted was determined taking into account the applicable provisions (Ustawa, 2011) referring to the regulation of the MSW regarding the minimum requirements for the number of water rescuers ensuring constant control of a designated water area (Rozporządzenie, 2012), where one lifeguard was on duty at the 25 -meter sports pool. The model of simulated rescue operation consisted of lifeguard stride entry into the water with a rescue tube, rescue front crawl swimming on the distance of 20 meters, dynamic headfirst surface dive, diving to the rescue dummy on the distance of 5 meters, extracting the rescue dummy on the surface of water, securing the rescue dummy by using the rescue tube, the return towing the rescue dummy in a way used in case of passive person on the distance of approximately 23-24 meters, lifeguard getting out of the water, pulling out the rescue dummy of the water on the shore, proceeding to the CPR (Figure 5). 


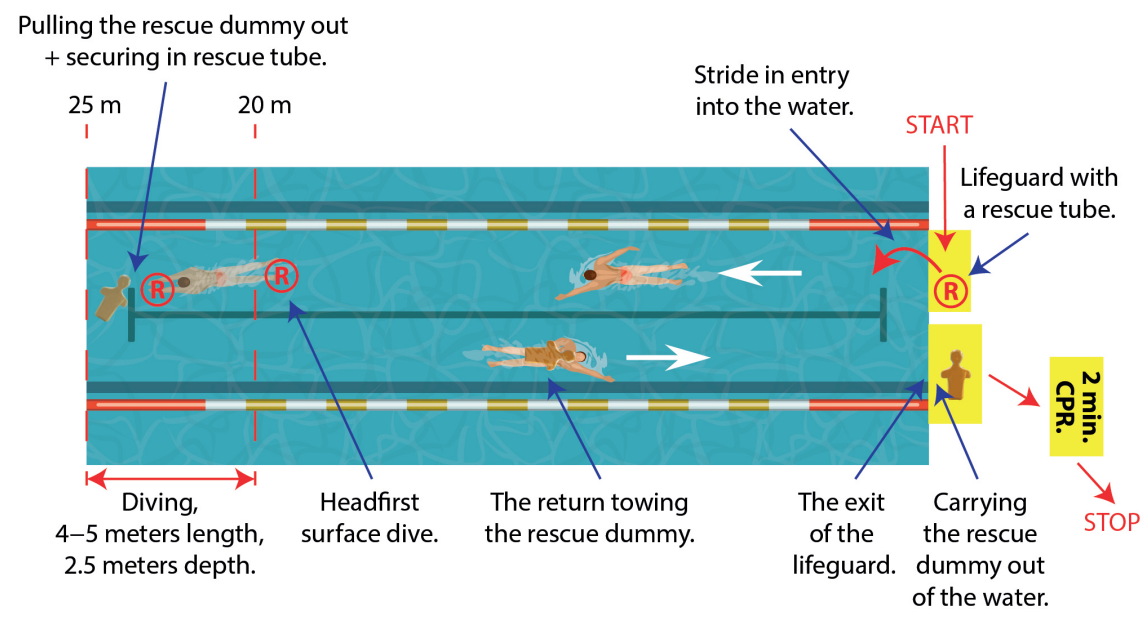

Figure 5. Scheme of a mock rescue operation in an indoor swimming pool up to $25 \mathrm{~m}$

The course of the two-minute "resuscitation by fatigued rescuer" action concerned the victim pulled out of the water and began in each case the same as in the case of "initial resuscitation". The results of each of the tested students were divided into the fitness part, in which the times of the mock rescue operation were recorded when the stopwatch was turned on at the start signal and turned off when the rescue dummy was placed on the edge of the pool, and the part where CPR procedures were performed (Figure 6). After completing the task, the highest value of pulse of each student between the end of the rescue operation in the water and commencement of CPR procedures was read. The indicators which were taken into account and used in the results chapter are:

1. Time of the action with the participation of a lifeguard, when performing rescue tasks with maximum commitment (time) ${ }^{1}$.

2. Post-exercise heart rate recorded after the end of the rescue operation in water but before the start of resuscitation procedures (heart rate/min.) $)^{2}$.

3. The general result is the result of all other indicators reported by the application (relaxation, depth of compressions, rate, the proportion of breathing in \%).

4. Relaxation - an appropriate way of releasing the chest after pressing (\%).

5. Compression depth - correct should be in the middle of the chest at the bottom of the sternum to a depth of $5 \mathrm{~cm}$, but not more than $6 \mathrm{~cm}(\%)$.

6. Compression rate - the average number of compressions per minute; the correct rate is $100-120 / \mathrm{min}$. (\%).

7. Share of breaths - the quality of rescue breaths given (quantity, time and strength with which they are given - in \%).

8. The ratio of compressions to rescue breaths - the correct value of this indicator is 30/2.

\footnotetext{
${ }^{1}$ Indicator examined in the second part of the study, which used fatigue of the rescue operation and post-exercise heart rate.

2 Indicator not taken into account in the tabular distribution of results.
} 

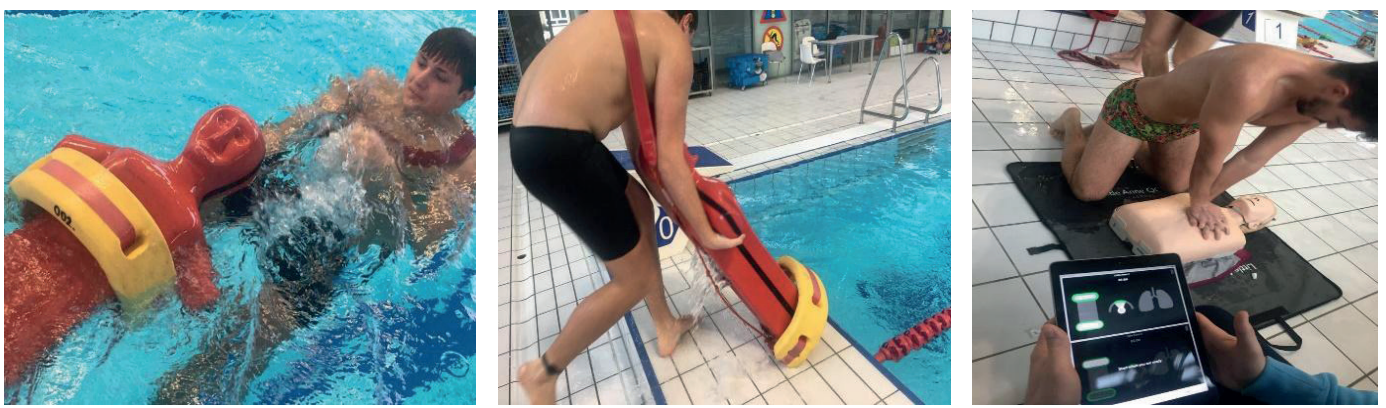

Figure 6 . Fragments of the model rescue operation

\section{Results}

The data collected during the research underwent statistical treatment using the Statistica 12 application. Basic data analysis presents the general characteristics of the listed variables (in the system before and after the effort made), the tested group of students based on location and dispersion measures. Then, an analysis of the correlation between selected variables was carried out, and also to check the differences in the results obtained regarding the elements of the rescue operation before and after the student's effort (appropriate tests of significance of differences).

Based on selected statistical parameters (Table 1 and 2): arithmetic mean $\left(x_{\text {śr }}\right)$, median $(\mathrm{Me})$, modal $(\mathrm{Mo})$, minimum (Min) and maximum (Max), quartile $1\left(Q_{1}\right)$, quartile $3\left(Q_{3}\right)$, standard deviation(s), coefficient of variation $\left(V_{s}\right)$, relating to the results measured before and after exercise, it can be stated that:

1. The general result is more satisfactory in the case of post-exercise CPR procedures.

2. The number of students performing flawlessly depth of compressions before and after exercise is very similar and amounts to $14-15$ people.

3. In the case of the relaxation indicator, there is a difference in the number of people performing correct releasing of the chest by up to 11 people in favor of the action in the fatigue of the rescuer.

4. The vast majority of students, both before and after exercise, performed the Compression Depth element best $\left(M o=100 ; M e=100 ; Q_{3}=100\right)$.

5. The results of students in relation to conducted rescue operations (before and after exercise) differed the most in relation to the rate of compressions $\left(V_{s}=35.5 \% ; V_{s}=37.2 \%\right)$; while the least in the share of breaths/before exercise $\left(V_{s}=9.2 \%\right)$ and the depth of compressions/after exercise $\left(V_{s}=0.6 \%\right)$.

The measurement results also indicate that the number of people who correctly performed the ratio of compressions to given breaths (30/2) before effort was $100 \%$, while after effort it was $38.5 \%$ (i.e. 10 people). 
Tahle 1. Summary of statistical parameter values for pre-exercise study results (\%)

\begin{tabular}{lcrrrrrrrrr}
\hline \multicolumn{1}{c}{ Indicator } & \multicolumn{1}{c}{$\mathrm{x}_{\text {śr }}$} & Me & Mo & $\begin{array}{c}\text { Cardinality } \\
\text { Mo }\end{array}$ & Min. & Max. & $\mathrm{Q}_{1}$ & $\mathrm{Q}_{3}$ & $\mathrm{~s}$ & $\mathrm{~V}_{\mathrm{s}}$ \\
\hline General & $\mathbf{8 7 . 8}$ & 98.0 & Multiple & 7 & 23.0 & 99.0 & 88.0 & 99.0 & 21.0 & 23.9 \\
Relaxation & 77.5 & 86.0 & 100.0 & 4 & 21.0 & 100.0 & 65.0 & 98.0 & 24.1 & 31.1 \\
Compression depth & 91.6 & 100.0 & 100.0 & 14 & 43.0 & 100.0 & 97.0 & 100.0 & 17.8 & 19.5 \\
Rate & 79.9 & 93.0 & 100.0 & 5 & 0.0 & 100.0 & 63.0 & 99.0 & 28.4 & 35.5 \\
Share of breaths & 92.4 & 96.0 & 97.0 & 5 & 65.0 & 100.0 & 90.0 & 98.0 & 8.5 & 9.2 \\
\hline
\end{tabular}

Table 2. Summary of statistical parameter values for post-exercise study results

\begin{tabular}{|c|c|c|c|c|c|c|c|c|c|c|}
\hline & & & & & & & & & & \\
\hline & $x_{\text {śr }}$ & $\mathrm{Me}$ & Mo & $\begin{array}{c}\text { Cardinality } \\
\text { Mo }\end{array}$ & Min. & Max. & $Q_{1}$ & $Q_{3}$ & $s$ & $V_{s}$ \\
\hline Time of the action/s & 87.0 & 88.5 & Multiple & 2 & 58.0 & 140.0 & 72.0 & 99.0 & 20.45 & 23.52 \\
\hline Heart rate after effort/number & 141.2 & 142.0 & Multiple & 4 & 104.0 & 164.0 & 136.0 & 148.0 & 13.31 & 9.43 \\
\hline General (\%) & 92.2 & 93.5 & 99 & 6 & 65.0 & 100.0 & 89.0 & 99.0 & 8.12 & 8.81 \\
\hline Relaxation (\%) & 92.5 & 100.0 & 100 & 15 & 19.0 & 100.0 & 97.0 & 100.0 & 18.61 & 20.12 \\
\hline Compression depth (\%) & 99.5 & 100.0 & 100 & 15 & 98.0 & 100.0 & 99.0 & 100.0 & 0.58 & 0.58 \\
\hline Rate (\%) & 75.3 & 88.5 & Multiple & 3 & 0.0 & 100.0 & 63.0 & 97.0 & 28.02 & 37.21 \\
\hline Share of breaths $(\%)$ & 81.9 & 89.0 & 100 & 8 & 0.0 & 100.0 & 75.0 & 100.0 & 25.83 & 31.53 \\
\hline
\end{tabular}

Before proceeding with further analysis of the results of the carried out test, it was necessary to decide whether the variables tested had a normal distribution. This was done using the W Shapiro-Wilk test (Table 3). The results of the W Shapiro-Wilk test to assess the normality of the distribution of variables measured before exercise $\left(\mathrm{H}_{0}\right.$ : The distribution of the studied variable is a normal distribution; assumed level of significance $\left.\leq 0.05\right)$.

Tahle 3. Assessment of distribution normality by W Shapiro-Wilk test before physical effort (\%)

\begin{tabular}{lcc}
\hline \multicolumn{1}{c}{ Variables/indicators } & The value of the W Shapiro-Wilk test & Level of significance $\mathrm{p}^{*}$ \\
\hline General & 0.582 & 0.000 \\
Relaxation & 0.853 & 0.002 \\
Compression depth & 0.524 & 0.000 \\
Rate & 0.725 & 0.000 \\
Share of breaths & 0.767 & 0.000 \\
\hline
\end{tabular}

Computer level of significance; if $\mathrm{p}<\left\langle\right.$ then $\mathrm{H}_{0}$ should be rejected.

As can be seen from the table presenting the results of the distribution normality test, no indicator has a normal distribution. The consequence of this is the use of nonparametric correlation based on the Spearman rank correlation coefficient, which allowed the assessment of the correlation between these variables (Table 4). 
Table 4. The use of nonparametric correlation based on Spearman's rank coefficient (\%)

\begin{tabular}{|l|l|l|l|l|l|}
\hline Indicator & General & Relaxation & Compression depth & Rate & Share of breaths \\
\hline General & 1.000 & $0.396^{*}$ & $0.532^{*}$ & $0.491^{*}$ & $0.796^{*}$ \\
\hline Relaxation & & 1.000 & 0.285 & $0.475^{*}$ & 0.174 \\
\hline Compression depth & & & 1.000 & 0.293 & $0.428^{*}$ \\
\hline Rate & & & & 1.000 & 0.292 \\
\hline Share of breaths & & & & 1.000 \\
\hline
\end{tabular}

Statistically significant results for $\leq 0.05$.

Considering the use of nonparametric correlation based on Spearman's rank coefficient, each of the indicators listed in Table 4 significantly correlates (positive correlation) with the "general" indicator; the strongest correlation relationship occurs between the general indicator and the indicator expressed by the share of breaths. The other two values occur in the case of relaxation and compression rate $(0.475)$ as well as in the case of compression depth and the share of breaths (0.428). This means that people who achieved a high compression rate result also maintained a relatively high score in the depth of compression; as well as the correlation relationship between the depth of compressions and the share of breaths, which is a visible effect of properly performed resuscitation.

Considering the results obtained by students after the effort, which was based on the model of the rescue operation on the short pool and included: rescue jump, swimming, diving, recovering the injured person, securing the injured person, towing the injured person and evacuating the injured ashore and commencing CPR procedures - similarly, the normality of the distribution was assessed first (Table 5).

The results of the W Shapiro-Wilk test to assess the normality of the distribution of variables measured after physical effort $\left(\mathrm{H}_{0}\right.$ : the distribution of the studied variable is a normal distribution; assumed level of significance $\leq 0.05)$.

Table 5. Assessment of distribution normality by W Shapiro-Wilk test after physical effort

\begin{tabular}{lcc}
\hline \multicolumn{1}{c}{ Variables/indicators } & The value of the W Shapiro-Wilk test & Level of significance p \\
\hline Time of the action (s) & 0.946 & 0.183 \\
Heart rate after exercise (number of beats $/ \mathrm{min}$ ) & 0.953 & 0.270 \\
General (\%) & 0.821 & 0.000 \\
Relaxation (\%) & 0.473 & 0.000 \\
Compression depth (\%) & 0.702 & 0.000 \\
Rate (\%) & 0.824 & 0.000 \\
Share of breath (\%) & 0.719 & 0.000 \\
\hline
\end{tabular}


The results of the distribution normality test indicate that only the variables: "Time of the Action" and "Heart Rate After Exercise" have a normal distribution. Therefore, the Spearman rank correlation coefficient was similarly used (Table 6).

Table 6. Application of nonparametric correlation based on Spearman's rank coefficient

\begin{tabular}{|c|c|c|c|c|c|c|c|}
\hline Variable & $\begin{array}{l}\text { Time of the action } \\
\text { (s) }\end{array}$ & $\begin{array}{l}\text { Heart rate after exercise } \\
\text { (number of beats/min) }\end{array}$ & $\begin{array}{c}\text { General } \\
(\%)\end{array}$ & $\begin{array}{c}\text { Relaxation } \\
(\%)\end{array}$ & $\begin{array}{c}\text { Compression depth } \\
(\%)\end{array}$ & $\begin{array}{l}\text { Rate } \\
(\%)\end{array}$ & $\begin{array}{c}\text { Share of breath } \\
(\%)\end{array}$ \\
\hline Time of action (s) & 1.000 & $0.495^{*}$ & -0.091 & 0.102 & -0.134 & 0.015 & -0.084 \\
\hline \multicolumn{8}{|c|}{$\begin{array}{l}\text { Heart rate after exercise } \\
\quad \text { (post exercise heart rate?) }\end{array}$} \\
\hline (number of beats/min) & & 1.000 & -0.059 & 0.088 & 0.058 & $-0.465^{*}$ & 0.108 \\
\hline General (\%) & & & 1.000 & 0.329 & -0.108 & 0.275 & $0.810^{*}$ \\
\hline Relaxation (\%) & & & & 1.000 & 0.045 & 0.172 & 0.281 \\
\hline Compression depth (\%) & & & & & 1.000 & -0.087 & -0.137 \\
\hline Rate (\%) & & & & & & 1.000 & 0.030 \\
\hline Share of breath (\%) & & & & & & & 1.000 \\
\hline
\end{tabular}

"Statistically significant results for $\leq 0.05$.

In the case of the values presented in Table 6, there are also presented two post-exercise indicators: time of the action and post-exercise heart rate, which are an assessment of the lifeguard's fitness. In the case of results showing statistically significant correlations, the correlation occurring in the case of the pulse rate and the time of the action (0.495), which indicates that the time of the action lengthened in people who finished the action with a higher heart rate, deserves attention. On the other hand, the compression rate index shows a negative correlation with the rescuer's post-effort heart rate $(-0.465)$ - the higher the rescuer's post-effort heart rate, the lower (worse) the quality of the correct pressure rate. In turn, taking into account the components of the rescue operation, similar to the situation before exercise, the result indicates a strong correlation between the quality of rescue breaths given and the general result of the rescue operation, although between the other components such as rate, depth of pressure or relaxation and the general result there is no statistically significant correlation.

Having two measurements (before and after exercise) of the same group of students, for selected indicators, it was checked whether the results obtained differ significantly from each other, and therefore whether the effort affects the quality of the rescue operation. In this case, the test for two dependent samples was used, i.e. the Wilcoxon (T) pair order test (Table 7).

Table 7. Results for the Wilcoxon test (\%)

\begin{tabular}{lcc}
\hline \multicolumn{1}{c}{ Parameters } & T test value & p value \\
\hline General before \& general after & 131.500 & 0.597 \\
Relaxation before \& relaxation after & 61.500 & 0.011 \\
Compression depth before \& compression depth after & 26.000 & 0.017 \\
Rate before \& rate after & 135.500 & 0.679 \\
Share of breaths before \& share of breaths after & 95.500 & 0.119 \\
\hline
\end{tabular}


Comparing the results of the general assessment of the rescue operation, as well as the assessment of the rate and share of breaths, the values do not differ statistically, so the physical effort preceding the action generally (especially taking into account the general rating) does not affect the quality of the action. This confirms the good preparation of WOPR rescuers to conduct a reliable rescue operation, even in the situation of an additional factor which is physical fatigue caused by a rescue operation.

In relation to the other indicators, the results of the components of the rescue operation elements, measured before and after the exercise (relaxation and compression depth) differ statistically significantly. The physical effort had an impact on these components.

\section{Discussion and conclusions}

An experiment consisting of checking whether the quality of cardiopulmonary resuscitation procedures will depend on fatigue and after the given physical effort of the rescuer who took these actions. The research included a number of "indicators" that were compared with each other by various statistical methods that can be used to summarize the results:

1. The general result (indicator) is more satisfactory in the case of CPR performed by a rescuer after exercise.

2. The vast majority of students, both before and after exercise, best performed the CPR fragment associated with the depth of compression indicator ( $\left.M o=100 ; M e=100 ; Q_{3}=100\right)$.

3. In the case of the relaxation indicator, there is a difference in the number of people performing correct chest releasing, up to 11 in favor of the action in fatigue of the rescuer.

4. The number of students who provide the correct depth of compressions before and after exercise is very similar and amounts to $14-15$ people.

5. The results of students in relation to rescue operations (before and after exercise) differed the most in relation to the rate of compressions $\left(V_{s}=35.5 \% ; V_{s}=37.2 \%\right)$; while the least in the share of breaths/before exercise $\left(V_{s}=9.2 \%\right)$ and the depth of compressions/after exercise $\left(V_{s}=0.6 \%\right)$.

6. The measurement results also indicate that the number of people who correctly performed the ratio of compressions to given breaths (30/2) before exercise was $100 \%$, while after the exercise it was $38.5 \%$ (i.e. 10 people).

7. Each of the indicators listed in Table 4 significantly correlates (positive correlation) with the "general" index; the strongest correlation relationship exists between the general index and the index expressed as the share of breaths.

8. The other two values occur in the case of relaxation and compression rate $(0.475)$ as well as in the case of compression depth and the share of breaths $(0.428)$ and are statistically significant.

9. In the case of results showing statistically significant correlations, the correlation occurring in the case of the pulse rate and the time of the action, which is 0.495 , which indicates that the time of the action lengthened among people who finished the action with a higher heart rate, deserves attention. On the other hand, the compression rate index calculates the negative correlation with the rescuer's post-effort heart rate $(-0.465)$ - the higher the rescuer's post-workout heart rate is, the lower (worse) the quality of the compression rate adjustment becomes.

Based on the summary of results above, the following conclusions can be sorted out: 
1. Fatigue of the rescuer with a short rescue operation at the 25 -meter pool in the given action model did not affect the quality of the two-minute CPR resuscitation performed on the QCPR anatomic model.

2. Fatigue of the rescuer with a short rescue action in the 25-meter pool, in the given action model, had a positive effect on the observance of relaxation and had no negative impact on the depth of chest compressions.

3. The features examined on which fatigue had a negative impact were:

- the rate of compressions, which in the case of the rescuer after the action, was the indicator with the highest level of disturbance, which means that maintaining a stable, correct rhythm of performed compressions is difficult to achieve by a fatigued rescuer,

- the ratio of compressions to given breaths, in which a significant number of rescuers were wrong about the number of both compressions and given rescue breaths.

4. The rescuer's physical condition is reflected in the pulse rate. The duration of action increased for people who had a higher heart rate after physical effort.

The above data indicate the validity of the research in the direction of certain variables occurring in the human relation and performed rescue tasks. It would seem that a tired rescuer will be less effective in their actions. The applied model of the rescue operation turned out to be so mild in the context of the adaptation of the rescuer's body that it had a mobilizing effect on them and thus on the quality of resuscitation procedures. Consideration should be given in further research to extending the rescue operation in water or the duration of CPR operations. However, it should be remembered that both rescue operations in the swimming pool are, due to the characteristics of the reservoir, shorter than those in open waters, as well as the first minutes of CPR activities are the most important. These considerations allow us to draw the most important conclusion that good preparation of lifeguards for conducting a reliable rescue operation, even in the situation of an additional factor which is physical fatigue as a rescue operation, is a priority value.

\section{Referencess}

Barcala-Furelos, R., Abelairas-Gomez, C., Romo-Perez, V., Palacios-Aguilar, J. (2013). Effect of psychical fatigue on the quality CPR: a water rescue study of lifeguards' physical fatigue and quality CPR in a water rescue. American Journal of Emergency Medicine, $31,473-477$.

Carballo-Fazanes, A., Barcala-Furelos, R., Eiroa-Bermúdez, J., Fernández-Méndez, M., Abelairas-Gómez, C., Martínez-lsasi, S., Murciano, M., Fernández-Méndez, F., Rodríguez-Núñez, A. (2019). Physiological demands of quality cardiopulmonary resuscitation performed at simulated 3250 meters high. A pilot study. American Journal of Emergency Medicine.

Meddings, D., Hyder, A., Ozanne-Smith, J., Rahman, A. (2014). Global report on drowning: preventing a leading killer. Geneva: Press World Health Organization.

Grasner, J.T., Bossaert, L. (2013). Epidemiology and management of cardiac arrest: what registries ere revealing. Best Pract Res Clin Anaesthesiol., 27, 293-306.

Lilja, G., Nilsen, N., Friberg, H., Horn, J., Kjaergaard, J., Nilsson, F., Pellis, T., Wetterslev, J., Wise, M., Bosch, F., Bro-Jeppesen, J., Brunetti, I., Buratti, A., Hassager, C., Hofgren, C., Insorsi, A., Kuipel, M., Martini, A., Palmer, N., Rundgren, M., Rylander, C., Van Der Veen, A. (2015). Cognitive function in survivors of-out-of hospital cordiac arrest after target temperaturę management at 33 degrees $C$ wersus 36 degrees C. Circulation, 131, 1340-1349.

Queiroga, C., Barcala-Furelos, R., Abelairas-Gomez, C., Garcia-Soidan, J. (2014). CPR quality reduced due to physical fatigue after a water rescue in a swimming pool. Signa Vitae, 9 (2), 25-31.

Rozporządzenie MSW z dnia 23 stycznia 2012 r. w sprawie minimalnych wymagań dotyczących liczby ratowników wodnych zapewniających stałą kontrolę wyznaczonego obszaru wodnego. 
Sánchez-López, M., Rovira-Gil, E., González-García, A., Ferrer-López, V., Martínez-Vizcaíno, V. (2015). Sex differences in the effort indicators during cardiopulmonary resuscitation maneuvers on rescue dummies. European Journal of Emergency Medicine: Official Journal of the European Society for Emergency Medicine [Eur J Emerg Med], 22 (1), 62-65.

Savastano, S., Vanni, V. (2011). Cardiopulmonary resuscitation real life: the most frequent fears of lay rescuers. Resuscitation, 82, $568-571$.

Stanisz, A. (2006). Przystępny kurs statystyki. Tom 1. Statystyki podstawowe. Kraków: StatSoft Polska Sp. z 0.0.

Stanula, A. (2008). Wpływ zmęczenia indywidualną akcją ratowniczą na skuteczność zabiegów resuscytacyjnych. Sporty Wodne i Ratownictwo, pp. 49-55.

Sulovic, L., Pavlovic, A., Zivkovic, J., Zivkovic, Z., Filipovic, S., Trpkovic, S. (2018). Accidental Drowning: The Importance of Early Measures of Resuscitation for a Successful Outcome. Case Reports in Emergency Medicine, 6 (4), 1-4.

Sulzgruber, P., Kliegel, A., Wandaller, C., Uray, T., Losert, H., Laggner, A., Sterz, F., Kliegel, M. (2015). Survivors of cardiac arrest with good neurological outcome show considerable impairments of memory functioning. Resuscitation, 88, 120-5.

Szpilman, D., Soares, M. (2004). In - water resuscitation - is it worthwhile? Resuscitation, pp. 25-31.

Szpilman, D., Webber, J., Quan, L., Bierens, J., Morizot-Leite, L., Langendorfer, J., Beerman, S., Lofgren, B. (2014). Creating a drowning chain of survival. Resuscitation, pp. 49-52.

Ustawa z 8.09.2006 o Państwowym Ratownictwie Medycznym.

Ustawa z 18.08.2011 o bezpieczeństwie osób przebywających na obszarach wodnych.

Wallis, B.A., Watt, K., Franklin, R.C., Taylor, M., Nixon, J.W., Kimble, R.M. (2015). Interventions associated with drowning prevention in children and adolescents: systematic literature review. Pub Med, pp. 195-210.

Winkler, B., Hartig, F., Ducanto, J., Koch, A., Georgieff, M., Lungwitz, Y., Muth, C. (2015). Helicopter-based in-water resuscitation with chest compressions: a pilot study. Emergency Medicine Journal, 32 (7), 553-558.

Wytyczne resuscytacji (2015). J. Anders (ed.) (2016). Kraków.

Cite this anticle aS: Olejniczak, R. (2020). Effectiveness of Cardiopulmonary Resuscitation Depending on Lifeguard's Level of Exhaustion. Central European Journal of Sport Sciences and Medicine, 2 (30), 57-70. DOI: 10.18276/cej.2020.2-06. 